Batenburg, R., Walbeek, W. van, Maur, W. in der. Belbin role diversity and team performance: jo there a relationship? Journal of Management Development: 2013, 32(8), 901-913

\begin{tabular}{|l|l|}
\hline $\begin{array}{l}\text { Postprint } \\
\text { Version }\end{array}$ & 1.0 \\
\hline Journal website & http://www.emeraldinsight.com/journals.htm?articleid=17095279 \\
\cline { 2 - 2 } Pubmed link & \\
\hline DOI & $10.1108 / J M D-08-2011-0098$ \\
\hline
\end{tabular}

This is a NIVEL certified Post Print, more info at http://www.nivel.eu

\title{
Belbin role diversity and team performance: is there a relationship?
}

\author{
RONALD BATENBURG ${ }^{1}$ AND WOUTER VAN WALBEEK AND WESLEY IN DER MAUR ${ }^{2}$ \\ ${ }^{1}$ Department of Information and Computing Sciences, Utrecht University, Utrecht, The \\ Netherlands, and NIVEL, Netherlands Institute for Health Services Research, Utrecht, The \\ Netherlands, \\ ${ }^{2}$ Deloitte Consulting, Amstelveen, Amsterdam, The Netherlands
}

\begin{abstract}
Purpose - This paper aims to test the relationship between team role diversity and team performance, as one of the main assumptions behind the highly cited and used Belbin model and test.

Design/methodology/approach - Data were collected among 24 teams of 144 students that participated in different rounds of a management game. All students performed a Belbin role self-test prior to the management game. Performance of the teams was measured by the grade they received for the yearend report written, and the financial results they achieved at the end of the management game.

Findings - No relationship was found between team role diversity and team performance. Also, it was found that the Belbin role of the team leader was not related to team performance as well. The only significant relationship found was between the individual study results of the team members and the grade they received for the year-end report.

Research limitations/implications - Results might change if team performance is measured by other indicators, such as the level of in-team collaboration or collective motivation.

Practical implications - It should not be expected that creating diversity of roles within teams automatically leads to better performance. Continuous improvement, recognizing the phase team development is in, should also be in place to balance team members and support their performance.

Originality/value - This paper contributes to the empirical testing of assumptions and ideas behind Belbin's model and test. Given its limitations, it provides new triggers to conduct more, similar empirical research.
\end{abstract}


Batenburg, R., Walbeek, W. van, Maur, W. in der. Belbin role diversity and team performance: is there a relationship? Journal of Management Development: 2013, 32(8), 901-913

\section{INTRODUCTION}

The continuous-changing competitive environment for organizations has instilled the need for flexibility and performance. Organizing "production" in an organization on the basis of team working is a popular method to cope with these challenges. Katzenback and Smith (1993) said that "teams will become the primary unit of performance in high-performance organizations.” Today there is a widespread recognition that much of the work accomplished in business and industry is the result of team effort. This has led to a greater need to find methods to make teams more effective (Kozlowski and Ilgen, 2006). In this paper we use the definition of Brannik, Salas, Prince who define a team to be two or more people with different tasks who work together adaptively to achieve specified and shared goals (Brannik et al., 1997).

Being an effective team depends on many factors. Factors that can vary between teams are mentioned by Larson and Lafasto and are a clear elevating goal, a resultdriven structure, competent team members, united commitment, a collaborative climate, standards of excellence, external support and recognition and principles leadership (Larson and LaFasto, 1989). In this paper we specifically focus on Belbin's proposition on the influence of team composition and leadership type on team performance, by presenting the results of an empirical research. Being one of the most influential theories on team composition and performance, we argue that Belbin's theory is (and remains) highly relevant to be scientifically evaluated and tested.

This paper follows the following structure. We start with outlining the theoretical background, defining the definitions and previous research on the subject. The management game section describes the setting in which the research data were obtained. The management game section is followed by the methods and results chapter and ends with a discussion on the results.

\section{Theoretical background}

Because of the importance of teams and teamwork in organizations a lot of research has been focussed on how to achieve high-performing teams. One of the most renowned and widely used team role framework in-team composition development and management development is constructed by Belbin (1993, 2010). Belbin's research revealed that the difference between successful and unsuccessful teams was not dependent on factors such as intellect and experience but primarily on behavior, the way team members make decisions, interact with one another and apply their capabilities to reach the team result.

Belbin observed that individuals in teams tend to assume different "team roles" defined as "a tendency to behave, contribute and interrelate with others in a particular way." Belbin found successful teams were characterized by the compatibility of the roles that their members played while unsuccessful teams were subject to role conflict (personality clashes, conflict, lack of co-operation) originating in role surplus/mismatch and/or missing needed "behavior" roles.

That is why Belbin argued that the method of the composition of the identified team roles to form a team proved decisive for the team success and therefore one of the most important factors influencing team performance.

Team roles as used in this research are based on Belbin's $(1993,2010)$ team roles. 
Batenburg, R., Walbeek, W. van, Maur, W. in der. Belbin role diversity and team performance: is there a relationship? Journal of Management Development: 2013, 32(8), 901-913

These team roles are depicted in eight roles differing on various personality characteristics and in-group behavior clustered within three team role "arch types": action-oriented roles, people-oriented roles and thinking/problem-solving-oriented roles. Team balance is described as "a spread of personal attributes in a team" which in this context means as much as the spread of the eight roles and the three team role clusters over the members of a team.

Belbin $(1993,2010)$ identified eight team roles that are displayed in Table I. In later research (Belbin, 1993, 2010) a ninth team role was identified: "the specialist" who contributes in-depth knowledge of a key area but has a tendency to focus narrowly on their own subject of choice, and to prioritize this over the team's progress. This role was identified when research on the Belbin team roles was tested in the real world where roleswith in-depth knowledge exist. Because our research consists of "new" assignments performed by relatively "knowledge blank" students this ninth role plays no role.

Therefore, we decided not to include the ninth role in the team role research.

\section{Previous research on team balance and performance}

Team performance in research using Belbin's framework is usually defined in terms of a quantifiable output or a self-assessment of team members regarding their own team performance (Belbin, 1993, 2010; Senior, 1997; Partington and Harris, 1999). In Belbin's work (Belbin, 1993, 2010; Dulewicz, 1995), team performance was measured in terms of winning and losing. Partington and Harris (1999) defined team performance as a measure of the team's output and how it meets the quality standards of those who have to use it and is perceived. Also social cohesiveness, team learning, personal well-being and the satisfaction that team members expressed with the team experience and achievement, for example, the grade obtained on a project, are mentioned (Werner and Lester, 2001). Van de Water et al. (2008) combined both financial team results and assessment to measure team performance. In this empirical study also both quantifiable (content) and assessment were used in assessing team performance.

\section{[TABLE 1]}

The results of previous studies considering team composition/team balance and team performance are ambiguous. Besides Belbin's positive results (Belbin, 1993, 2010) other research shows weak support (Senior, 1997; Park and Bang, 2002) or did not show support for this proposition at all (Partington and Harris, 1999; Van de Water et al., 2008). Despite these findings the Belbin role theory remains popular. That is why in this paper not only the relationship between team balance and team performance is looked upon, but also the statement Belbin's research is based on: "difference between success and failure for a team was not dependent on factors such as intellect or individual performance, but more on behaviour.” In Table II an overview is given of research focussed on the relationship between balance and performance. For each research the operationalization of both balance and performance has been given.

\section{Leadership team role and team performance}


Batenburg, R., Walbeek, W. van, Maur, W. in der. Belbin role diversity and team performance: is there a relationship? Journal of Management Development: 2013, 32(8), 901-913

Turner and Müller (2005) consider effective leadership a success factor in organizations and that an appropriate leadership style can lead to better performance. Belbin's $(1993,2010)$ research showed that coordinator and shaper, are the two archetypal team leader roles. Belbin identified the coordinator role as the "ideal" team leadership role, but that also the shaper role is found among top managers and CEO's, and correlating with successful (performing) teams. Other studies found coordinator and resource investigator roles among managers (Fisher et al., 2000) or that only resource investigator and team worker roles are correlated to performance as a team leader (Dulewicz and Higgs, 2003). In this research we look into the possible relationship between the role of the team leader and team performance.

\section{Quality of the individual and team performance}

But what makes the difference between a performing team and a non-performing team? Belbin $(1993,2010)$ found that the difference between success and failure for a team was not dependent on factors such as intellect, but more on behavior. However, Katzenback and Smith (1993) argued that no group ever becomes a performing team until it can hold itself accountable as a team. And that, when an individual is part of a team, he takes with him a set of talents, background, experience and prejudices. But is then the individual quality of team members the key to better team performance, and not necessarily the variation in-team composition? Belbin $(1993,2010)$ refers to the role of a team member and the presence of sufficient complementary roles that should encompass higher team performance. Given this antithesis, this research will also look into the quality of the respective team members and how that individual quality instead of team role variation impacts team performance.

\section{Hypotheses of the study}

In this study, we depart from Belbin's argument that teams with more complementary skills will perform better than teams with less complementary skills: $\mathrm{H} 1$. The more complementary (balanced) a team is in terms of the Belbin clusters and roles, the better the team will perform.

Second, we look into the proposition that teams with a coordinator, shaper, resource investigator or team worker Belbin role as team leader will perform better than teams with other leader types:

H2. Team leader role effects team performance.

And third we look into the relationship between individual quality of team members and team performance:

H3. The higher team average in term of individual quality/performance, the better the team will perform.

We will test these hypotheses by analyzing a sample of student teams in a semi experimental setting.

\section{[TABLE 2]}

\section{The management game: data and measures}

Data were collected among 144 undergraduate master students that participated in 24 teams, as part of a management game at Utrecht University during three academic 
Batenburg, R., Walbeek, W. van, Maur, W. in der. Belbin role diversity and team performance: is there a relationship? Journal of Management Development: 2013, 32(8), 901-913

years (2007/2008, 2008/2009 and 2009/2010). Although this is a rich data set that is feasible for testing the hypothesis, we acknowledge its limitations. While the data are collected from three business games in three different years these samples are different, the game content and the tutors were the same in all three years. A simulated business setting a management game is played by teams of six students that compete with each other during five weeks. The course started with a written exam. After this test students were allocated to a board role and a team based on a written application letters including an individually completed Belbin test. After all students delivered their application letters, the actual teams were formed by the teachers of the course. In this allocation process the quality of the application letter basically determined if student got the position they applied for.

A simulation program produced the results for each team based on the current decisions the teams made, their competitors' decisions, market trends and random events in the market as well as the state of the company in previous quarters. All companies had the same starting situation and an opportunity to do a test quarter. The simulation program calculated the market share for each brewery and beer type per brewery, turnover, profit and employee satisfaction and was based on an increase or decrease of these variables and the previous quarters.

At the end of each quarter, each team had to deliver a quarterly report in which each discipline (financial, HR, logistic, IT, etc.) had to elaborate on their actions in that quarter. Reports were reviewed using a standardized scoring table per discipline. If the alignment of the scores of each discipline within the team was high, the team would have a more favorable position in comparison to the other teams with a lower alignment score.

At the end of the management game, all teams had to write a year-end report and present the results to a board of supervisors. The grading of the year-end report was based on consistency of the content, whether theories and models were applied in the report, and the actual presentation.

The year-end report and presentation grade of each team can be considered as an indicator of team performance. In addition, all teams achieved an end position with the game, based on the (virtual) financial performance of their brewery after four quarters.

\section{RESULTS}

\section{Measuring team performance}

We start by describing the performance of all teams, as measured by: the end grade they received based on the year-end report; and the (virtual) financial results of their company after the last round of the management game.

Figure 1 first presents the variation in team grades by year. Grades are expressed by the Dutch grading system, ranging from 1 (lowest) to 10 (highest). In Dutch academic system, six is the threshold to pass.

For each year, there is a reasonable variation between teams in their grades, except from year 2008/2009 in which only six teams participated. The average team score was 7.48 in 2007/2008 (SD=0.75), 7.88 in 2008/2009 (SD=0.41) and 7.08 in 2009/2010 (SD=0.79). 
Batenburg, R., Walbeek, W. van, Maur, W. in der. Belbin role diversity and team performance: is there a relationship? Journal of Management Development: 2013, 32(8), 901-913

Our second performance measurement is the financial achievement at the end of the management game. Figure 2 presents this variation between teams. Financial achievement is expressed in (virtual) euros.

Compared to the team grades, there is a very large variation in financial results of the team. Due to the fierce competition and the sometimes risky strategic behavior of teams, some achieved very high losses or profit. This was especially the case in the academic year 2009/2010.

\section{Testing H1}

To test our first hypothesis (the more complementary (balanced) a team is in terms of the Belbin clusters and roles, the better the team will perform), Belbin team role complementarity or balance was calculated by two different measurements.

\section{[FIGURE 1][FIGURE 2]}

First, the number of different "original” Belbin roles within the team was counted. This measurement theoretically varies between 0 (all six members hold the same Belbin role) until 6 (all six members hold a different Belbin role). We recall that students did the standard Belbin test and were requested to select one of the eight roles as their dominant one, based on these test results. Although all of the Belbin roles appear to be present among the students in each academic year, some roles were more frequent than others.

For instance, the "goal-oriented integrater" role was the dominant role for 21 percent of the students, whereas the "researcher, developer, improviser" role came out as the dominant role for only 6 percent of all students. The other six roles varied between 16 and 9 percent of frequency. In terms of Belbin composition, most teams (70 percent) had five different roles (i.e. having two persons having the same Belbin role), 13 percent had six different roles (i.e. the full role variation possible), and 17 percent of the teams had four different roles.

Second, we measured the number of different clusters of Belbin roles within each team. To this end, we applied the clustering of the original eight roles into three clusters as presented earlier in Table I. From this, it appears that 41 percent of the students belong to the Belbin cluster c (thinking/problem-solving-oriented roles), 37 percent to Belbin cluster b (people-oriented roles), and 22 percent to Belbin cluster a (action-oriented roles). In terms of in-team variation, only two groups of teams can be distinguished, as 64 percent of the teams had all three clusters of Belbin roles present, while the other 36 percent consisted of two different clusters of Belbin roles. The next table shows if team performance, as measured by the year-end report grade and the financial achievement in the management game, differs between the complementarity/balance of the 24 teams, as expected by $\mathrm{H} 1$.

Table III shows that our $\mathrm{H} 1$ is not supported by the data. The average team performances differ between subgroups, but not systematically in the expected direction. The three teams with the highest diversity of six different Belbin roles, do not outperform the other teams. Actually, the four teams that have a medium diversity (five different Belbin roles) do perform above average with regard to the financial performance at the end of the management game, while the team with the lowest diversity (four different Belbin roles) performed best on the year-end report grade. 
Batenburg, R., Walbeek, W. van, Maur, W. in der. Belbin role diversity and team performance: is there a relationship? Journal of Management Development: 2013, 32(8), 901-913

The second measurement of Belbin role cluster complementarity, does not support $\mathrm{H} 1$ either. In contrast to the expectation, thee eight teams with three different Belbin role clusters perform less (on both indicators) compared to the teams that had members from only two different Belbin roles.

\section{Testing H2}

To test the second hypothesis, we broke teams according to the role of the CEO and analyzed the differences in their team performance. It is expected that team led by CEOs that have a role as coordinator, shaper, resource investigator or team worker perform better than teams led by other Belbin roles. Table IV shows the results. As can be expected, most CEOs of the student teams have the "Chairperson" as their main Belbin role. Teams led by this type of CEOs have an above average performance with regard to the year-end report grade (7.55), but not with regard to the financial endgame results (-751,624 euros). The second most common Belbin role of CEOs is "goal-oriented integrater." Teams led by this type of CEOs have an average year-end grade (7.43), but did achieve a relatively positive financial result at the end of the management game $(+1,096,018$ euros).

The breakdown analyses do not support the expectation that four types of CEO Belbin roles (teamworker/creator of new roads/analyst of problems and ideas/organizer) are related to higher team performance. The testing of this hypothesis is, however, clearly restricted by the small numbers of teams.

\section{[TABLE 3]}

\section{Testing H3}

Third and last, we tested the hypothesis describing the relationship between the average study skills of the team members and the team performance in the management game. The study skills of team members is indicated by an individual multiple choice exam that was taken one week before the start of the management game. The multiple choice exam consisted of 40 questions about a number of key concepts and models in strategic management, such as Porters' five forces model, Treacy and Wiersma value disciplines, portfolio marketing, and so on. Figure 3 shows the results of a (Pearson) correlation analysis, including a scattergram to plot the two team performance measurements.

The scattergram at the left hand side of Figure 3 and its $R_{2}$ value show that team performance and the average study skills of the team members are indeed positively related. This confirms H3. In contrast, however, H3 is not confirmed if team performance is measured by the financial results the teams achieved at the end of the management game. Teams with members that obtained high study results apparently did not outperformed the other teams in the management game.

\section{[TABLE 4][FIGURE 3]}

\section{CONCLUSION AND DISCUSSION}

In this paper we tested three different expectations with regard to team performance, building upon the theory and assumptions of the Belbin role classification and tests. 
Batenburg, R., Walbeek, W. van, Maur, W. in der. Belbin role diversity and team performance: is there a relationship? Journal of Management Development: 2013, 32(8), 901-913

Data were collected and analyzed from 24 teams consisting of six members each that participated in a management game as part of their business informatics master study at Utrecht University between 2007 and 2010. All students executed and reported a Belbin role self-test. The performance of the team was indicated by the grade received for the year-end report that had to be written after the management game, as well as the (virtual) financial results of their team (company) at the end of the management game.

The results show that, in contrast to the hypothesis, in-team Belbin role diversity is not correlated with team performance. This contradicts with the claim that role diversity (or: team role complementarity) contributes to the synergy of a team, and hence to team performance. Also, the Belbin role of the team leader, the CEO within the management game, is not related to team performance. What is partly confirmed by the data, is that the average study skills of the team members is correlated with team performance.

The absence of a relationship between diversity in Belbin team roles and team performance might be unexpected, it actually complies with a number of other studies that found a similar result (see Table II). Other factors could be of influence on team performance, such that the potential effect of role diversity is conditioned or "covered." Also, we acknowledge the actual measurements have their limitations. For instance, team performance is measured by two rather indirect indicators, which do not capture the actual level (or: success) of co-operation between the team members.

Still, from the management games that were studied, it could also be seen that the Belbin model and its test did support students to realize their team role in a competitive and high-pressure situation. In practice, insight in the Belbin roles helped them to find their individual strengths and weaknesses, and what it means to become a more effective team member. This might be an "indirect" or "spillover" effect of applying the Belbin test in management games, or project teams in general. Although students might differ with "real world" managers, the conditions under which they performed during the management game actually approach the daily reality of organizations and competitive environments. External jury members (experienced managers) who were invited to jury presentations and business documents of the student teams, confirmed that the management game has significant market reality value and set students in a realistic business situation. Finally, the results of this paper imply that managers should take multiple considerations into account when compiling their teams to cope with complex problems. As is often the case, they should not merely rely on anecdotal evidence provided by consultants and training organizations selling team-building programs that focus on teams that are supposed to start deliver results only. While there may be benefits from team-building programs offered by consultants, managers should be skeptical of simplistic claims that a team-building program will create a cohesive team and increase productivity. Creating cohesive and productive teams probably requires more effort than can be provided by setting diverse members together. What managers could do, is to use the provided theories and models as a starting point. It is important to acknowledge each team member's strengths and weaknesses in the forming phase, and build on that knowledge to improve team performance in the subsequent phases (as described by early work as in Tuckman, 1965 and principles of continuous quality improvement, Burton and Moran, 1995; Scholtes et al., 2003). 
Batenburg, R., Walbeek, W. van, Maur, W. in der. Belbin role diversity and team performance: jo there a relationship? Journal of Management Development: 2013, 32(8), 901-913

Ensuring the drive and incentive of each team member to deliver top team performance means constant teambuilding. Acknowledging in which phase the team is, and organize frequent feedback sessions, can facilitate this.

\section{REFERENCES}

Belbin, R.M. (1993), Team Roles at Work, Butterworth-Heinemann, Oxford.

Belbin, R.M. (2010), Management Teams: Why They Succeed or Fail, 3rd ed., ButterworthHeinemann, Oxford.

Brannik, M., Salas, E. and Prince, C. (1997), Team Performance Assessment and Measurement, Lawrence Erlbaum Associates, Mahwah, NJ.

Burton, T.T. and Moran, J.W. (1995), The Future Focused Organization, Prentice Hall PTR, Englewood Cliffs, NJ.

Dulewicz, V. and Higgs, M.J. (2003), "Design of a new instrument to assess leadership dimensions and styles", Henley Working Paper Series No. HWP 0311, Henley Management College, Henley-on-Thames.

Dulewicz, V.A. (1995), "Validation of Belbin's team roles from 16PF \& OPQ using bosses' ratings of competence", Journal of Occupational \& Organizational Psychology, Vol. 68 No. 2, pp. 81-99.

Fisher, S.G., Hunter, T.A. and Macrosson, W.D.K. (2000), "The distribution of Belbin team roles among UK managers", Personnel Review, Vol. 29 No. 2, pp. 124-140.

Katzenback, J. and Smith, K. (1993), "The discipline of teams", Harvard Business Review, March- April, pp. 111-120.

Kozlowski, S. and Ilgen, D. (2006), "Enhancing the effectiveness of work groups and teams", Psychological Science in the Public Interest, Vol. 7 No. 7, pp. 77-124.

Larson, C.E. and LaFasto, F.M. (1989), Teamwork: What Must Go Right, What Can Go Wrong, Sage, Newbury Park, CA.

Park, W.W. and Bang, H. (2002), "Team role balance and team performance", paper presented at Belbin's Biennial Conference, Changing Role of Management in the 21st Century, Clare College, Cambridge.

Partington, D. and Harris, H. (1999), "Team role balance and team performance: an emperical study", Journal of Management Development, Vol. 18 No. 8, pp. 694-1711.

Scholtes, P.R., Joiner, B. and Streibel, B. (2003), The Team Handbook: How to Use Teams to Improve Quality, Oriel, Madison, WI.

Senior, B. (1997), "Team roles and team performance: is there 'really' a link?", Journal of Occupational and Organizational Psychology, Vol. 70 No. 3, pp. 241-258.

Ten Haaf, W., Bikker, H. and Adriaanse, D.J. (2002), Fundamentals of Business Engineering and Management, Delft University Press, Delft.

Tuckman, B.W. (1965), "Developmental sequence in small groups", Psychological Bulletin, Vol. 63 No. 6, pp. 384-299.

Turner, J.R. and Mu" Iler, R. (2005), "The project manager's leadership style as a success factor on projects: a literature review", Project Management Journal, Vol. 36 No. 2, pp. 4961.

van de Water, H., Ahaus, K. and Rozier, R. (2008), "Team roles, team balance and performance", Journal of Management Development, Vol. 27 No. 5, pp. 499-512.

Werner, J.M. and Lester, S.W. (2001), "Applying a team effectiveness framework to the performance of student case teams", Human Resource Development Quarterly, Vol. 12 No. 4, pp. 385-402.

Further reading Paris, C.R., Salas, E. and Cannon-Bowers, J.A. (2000), "Teamwork in multiperson systems: a review and analysis", Ergonomics, Vol. 43 No. 8, pp. 1052-1075.

About the authors Ronald Batenburg is an associate professor at the Department of Information and Computing Sciences, Utrecht University, the Netherlands. He studies sociology and achieved his $\mathrm{PhD}$ in organization sciences. He is also a program leader at NIVEL, the Netherlands Institute for Health Services Research. He published in Information 
Batenburg, R., Walbeek, W. van, Maur, W. in der. Belbin role diversity and team performance: jo there a relationship? Journal of Management Development: 2013, 32(8), 901-913

and Management, Supply Chain Management and Research in the Sociology of Organizations. He is a member of the Editorial Board of the International Journal of electronic health care and the International Journal of Organizational Design and Engineering. Ronald Batenburg is the corresponding author and can be contacted at: r.s.batenburg@uu.nl Wouter van Walbeek is a manager at Deloitte, the Netherlands. He studied technology management and sociology at the University of Groningen. He published in the International Journal of Business Innovation and Research and business magazines.

Wesley in der Maur is a senior consultant at Deloitte, the Netherlands. He studied information science at Utrecht University. He published in the International Journal of Business Innovation and Research and business magazines.

\section{FIGURES AND TABLES}

Table I. Overview Belbinteam roles

\begin{tabular}{|c|c|c|c|}
\hline Cluster & & Role & Description of role \\
\hline \multirow[t]{3}{*}{ Action-oriented roles } & 1 & Implementer & $\begin{array}{l}\text { Concerned with the practical translation and } \\
\text { application of concepts and plans developed } \\
\text { by the team. This entails a down-to-earth } \\
\text { outlook, coupled with perseverance in the face } \\
\text { of difficulties }\end{array}$ \\
\hline & 2 & Completer/finisher & $\begin{array}{l}\text { Ensures that the team's efforts achieve } \\
\text { appropriate standards, and that mistakes of } \\
\text { both commissions and omissions are avoided. } \\
\text { It also involves searching for detailed } \\
\text { mistakes and maintaining a sense of urgency } \\
\text { within the team }\end{array}$ \\
\hline & 3 & Shaper & $\begin{array}{l}\text { Challenges, argues and disagrees. Is } \\
\text { achievement-motivated, extrovert, impatient, } \\
\text { and has a low frustration threshold. Keen on } \\
\text { winning the game. Has good insight, } \\
\text { especially if loses. A non-chair leader }\end{array}$ \\
\hline \multirow[t]{3}{*}{ People-oriented roles } & 4 & Coordinator & $\begin{array}{l}\text { Organizes, co-ordinates and controls the } \\
\text { activities of the team. This involves the } \\
\text { clarification of team objectives and problems, } \\
\text { assigning tasks and responsibilities, and } \\
\text { encouraging team members to get involved in } \\
\text { achieving objectives and goals }\end{array}$ \\
\hline & 5 & Team worker & $\begin{array}{l}\text { Creates and maintains a team spirit. This } \\
\text { involves improving communication by } \\
\text { providing personal support and warmth to } \\
\text { team members and by overcoming tension } \\
\text { and conflict }\end{array}$ \\
\hline & 6 & $\begin{array}{l}\text { Resource } \\
\text { investigator }\end{array}$ & $\begin{array}{l}\text { Explores the environment outside the team, } \\
\text { by identifying ideas, information and } \\
\text { resources. Performance of this role involves } \\
\text { developing contacts, co-ordination and } \\
\text { negotiation with other teams and individuals }\end{array}$ \\
\hline \multirow[t]{2}{*}{$\begin{array}{l}\text { Thinking/problem- } \\
\text { solving-oriented } \\
\text { roles }\end{array}$} & 7 & Monitor evaluator & $\begin{array}{l}\text { Analyses ideas and proposals being } \\
\text { considered by the team, to evaluate their } \\
\text { feasibility and value for achieving the team's } \\
\text { objectives. Points out in a constructive } \\
\text { manner the weaknesses of proposals being } \\
\text { considered }\end{array}$ \\
\hline & 8 & Plant & $\begin{array}{l}\text { Concerned with putting forward ideas and } \\
\text { strategies for achieving the objectives } \\
\text { adopted by the team. Performance of this role } \\
\text { requires creativity, imagination and } \\
\text { innovation }\end{array}$ \\
\hline
\end{tabular}

Source: Belbin $(1993,2010)$ 
Batenburg, R., Walbeek, W. van, Maur, W. in der. Belbin role diversity and team performance: jo there a relationship? Journal of Management Development: 2013, 32(8), 901-913

\begin{tabular}{ll}
\hline Reference & $\begin{array}{l}\text { Operationalisation of } \\
\text { team balance }\end{array}$ \\
\hline $\begin{array}{l}\text { Van de Water } \\
\text { et al. (2008) }\end{array}$ & $\begin{array}{l}\text { Partington and Harris } \\
\text { team balance } 1+2\end{array}$ \\
& $\begin{array}{l}\text { A balanced team is a team } \\
\text { with a score of } 5 \text { and up } \\
\text { base on the team } \\
\text { balancing construct of }\end{array}$ \\
& $\begin{array}{l}\text { Ten Haaf } \text { et al. (2002) } \\
\text { A balanced team is a team } \\
\text { where each role (SPI }>90)\end{array}$ \\
Park and & is represented
\end{tabular}

Partington and Harris (1999)

Senior (1997)

Belbin (1993, 2010)
Team balance is the aggregate of absolute deviations of the role mean from the ideal mean score

Team balance is the total score per team on each role being present on a high or very high level for at least one team member (1 point) and each role being not present (2 points) compared to an ideally balanced team Team balance is the total score per team of the number of times each role is present on a high or very high level plus 2 points for each team role not present compared to an ideally balanced team A balanced team is a team where each role (SPI > 70) is represented and when the mean scores on each team role is within 20 percentage points from one another

A balanced team is a team where each role (SPI > 70) is represented
Operationalisation of team performance

Financial team result in a management game and assessment

The perbeived performance on quality of work, quantity of work, frequency of innovation, reputation about work, goalattainment, efficiency and morale

Financial team result in a project management exercise

Research results

No significant relation between team balance and team performance No significant relation between team balance and team performance

Some support for the correlation of team balance and team performance

No significant relation between team balance and team performance

No significant relation between team balance and team performance

No significant relation between team balance and team performance

Assessment of actual and perceived performance using the repertory grid technique

Some support for the correlation of team balance and team performance

Financial team result in a management game
Significant correlation between team balance and team performance

Source: Inspired by Van de Water et al. (2008) 
Batenburg, R., Walbeek, W. van, Maur, W. in der. Belbin role diversity and team performance: jo there a relationship? Journal of Management Development: 2013, 32(8), 901-913

Figure 1. Team performance measured by grades of their yearend report



Figure 2.

Team grades measured by their virtual turn-over at the end of the management game

Table III. Performance of all teams, measured by yearend report grade and financial results at the end of the management game, by Belbin role diversity and tested on significance of within/between group variance

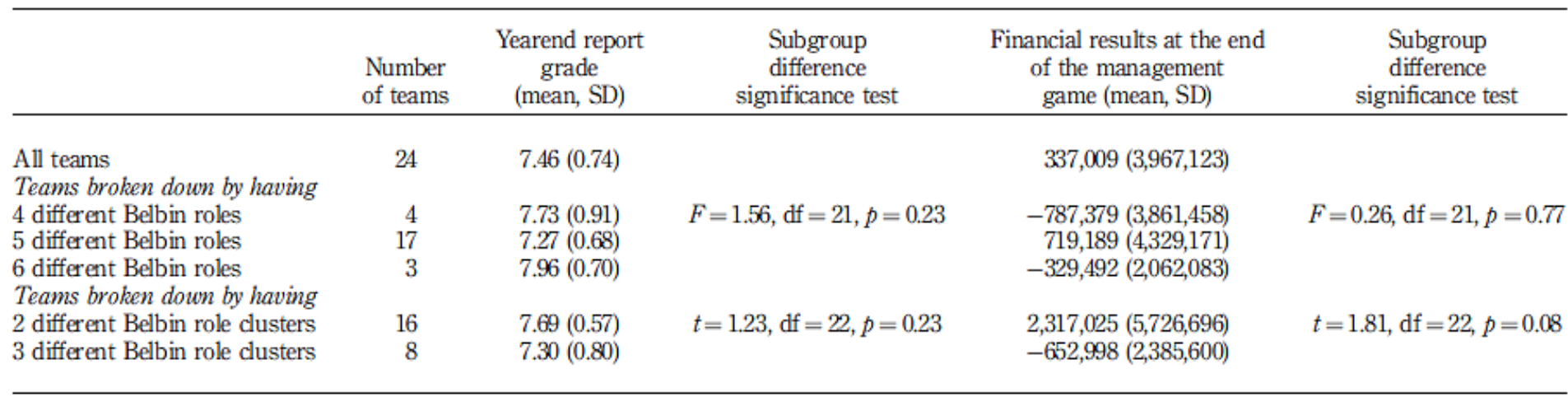


Batenburg, R., Walbeek, W. van, Maur, W. in der. Belbin role diversity and team performance: jo there a relationship? Journal of Management Development: 2013, 32(8), 901-913

\begin{tabular}{lccc}
\hline & $\begin{array}{c}\text { Number } \\
\text { of teams }\end{array}$ & $\begin{array}{c}\text { Yearend report } \\
\text { grade (mean, SD) }\end{array}$ & $\begin{array}{c}\text { Financial results } \\
\text { end of game } \\
\text { (mean, SD) }\end{array}$ \\
\hline All teams & 24 & $7.46(0.74)$ & $337,009(3,967,132)$ \\
Teams broken down by Belbin role of the CEO & & & \\
Teamworker, team coach, communicater & 1 & 6.00 & $-106,803$ \\
Creator of new roads, visionair & 1 & 8.30 & $13,251,541$ \\
Analyst of problems and ideas, criticaster & 3 & $7.25(0.98)$ & $-637,775(1,654,692)$ \\
Organizer, planner, executer & 2 & $7.88(0.18)$ & $-786,788(4,280,091)$ \\
Chairperson, prioritizer, delegater & 10 & $7.55(0.60)$ & $-751,624(2,578,319)$ \\
Goal-oriented integrater & 6 & $7.43(0.83)$ & $1,096,018(4,236,792)$ \\
Goal and deadline keeper & 1 & 6.60 & $-629,466$ \\
\hline
\end{tabular}

Figure 3.

Performance of all teams, measured by year-end report grade and financial results at the end of the management game, by study skills of team members (exam grade before management game)
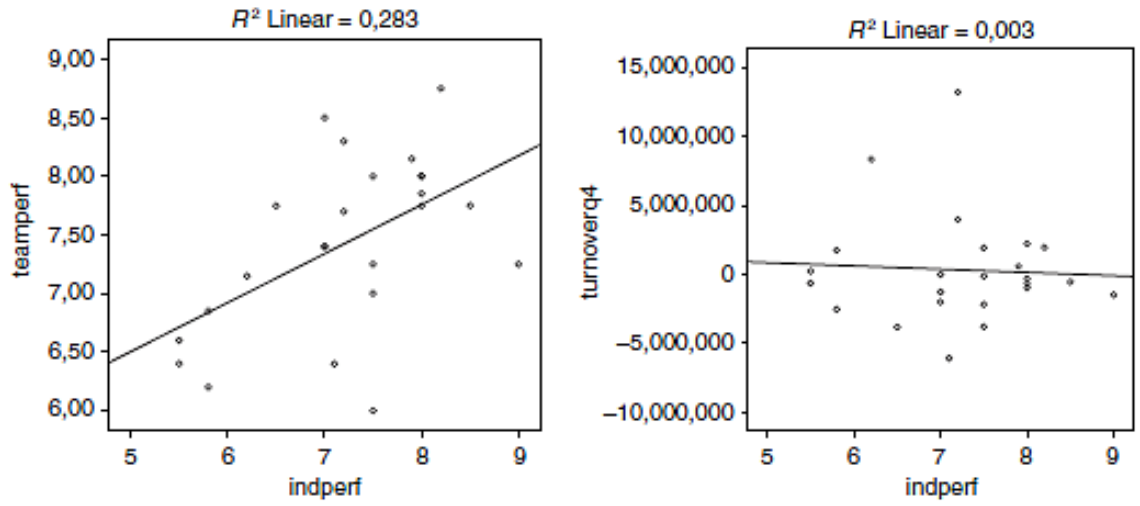